\title{
Aportes y retos para la comprensión del ser de la mujer latinoamericana desde la filosofía de la liberación de Enrique Dussel*
}

Fecha de entrega: 7 de diciembre de 2016

Fecha de evaluación: 16 de febrero de 2017

Fecha de aprobación: 20 de abril de 2017

\begin{abstract}
Diana Alejandra Díaz Guzmán**
\end{abstract}
\section{Resumen}

Teniendo en cuenta que solo es posible comprender el ser de la mujer latinoamericana superando la negación del ser del ente que ella es, el lector podrá encontrar una reflexión desde la filosofía de la liberación de E. Dussel en la que se evidencia la negación ontológica y práctica de la mujer, debido a la imposición de un modo de ser (ama de casa, objeto sexual, realización por medio del hombre, rol exclusivo de madre y educadora de los hijos) desde una totalidad sistémica falocrática. Por lo tanto, si se quiere superar dicha negación es necesario partir desde la analéctica dusseliana para comprender que la dominación erótica es un producto sociocultural en América Latina, puesto que la conquista y la colonización de este continente trajo como consecuencia nuevas formas de ser y estar en este territorio; hasta la aprehensión de nuevos conceptos y premisas (la potencia pasiva aristotélica, el poder-ser

\footnotetext{
* Este artículo forma parte del trabajo de grado El ser de la mujer latinoamericana desde la metafísica de la alteridad de la filosofía de la liberación de Enrique Dussel, presentado en el 2016 en la Universidad Pedagógica Nacional para optar al título de Licenciada en Filosofía. DOI: http://dx.doi.org/10.15332/ s0120-8462.2017.0117.03

**Egresada de la Licenciatura en Filosofía de la Universidad Pedagógica Nacional. ddiaz.sisifo@gmail.com
} 
dusseliano, el dejar ser al ente levinasiano) para dilucidar la afirmación del ser que ha sido negado para llegar a comprenderlo.

Palabras clave: América Latina, mujer latinoamericana, totalidadsistémica, ser, alteridad, potencia pasiva, poder-ser, ente.

\title{
Contributions and challenges for the understanding of the being of the Latin American woman from the philosophy of liberation of Enrique Dussel
}

\author{
Diana Alejandra Díaz Guzmán
}

\section{Abstract}

Considering that it is only possible to understand the being of the Latin American woman overcoming the denial of the being of the entity that she is, the reader will be able to find a reflection from the philosophy of the liberation of E. Dussel in which the ontological denial is evident and women's practice, due to the imposition of a way of being (housewife, sexual object, realization through man, exclusive role of mother and educator of children) from a phallocratic systemic totality. Therefore, if we want to overcome this denial it is necessary to start from the Dusselian analectics to understand that erotic domination is a sociocultural product in Latin America, since the conquest and colonization of this continent brought new ways of to be and being in this territory; to the apprehension of new concepts and premises (the Aristotelian passive potentiality, the Dusselian can-be, Levinasian the let being be) for elucidating the affirmation of the being that has been denied in order to understand it.

Keywords: Latin America, Latin American woman, systemic totality, being, alterity, passive potentiality, can-be, entity. 


\title{
Aportes e desafios para a compreensão do ser da mulher latino- americana desde a filosofia da libertação do Enrique Dussel
}

\author{
Diana Alejandra Díaz Guzmán
}

\section{Resumo}

Levando em consideração que só é possível compreender o ser da mulher latino-americana superando a negação do ser do ente que ela é, o leitor poderá encontrar uma reflexão desde a filosofia da libertação do E. Dussel na qual se evidencia a negação ontológica e pratica da mulher, devido à imposição de um modo de ser (dona de casa, objeto sexual, realização por meio do homem, rol exclusivo de mãe e educadora dos filhos) desde uma totalidade sistêmica falocrática. Por tanto, se quer superar esta negação é preciso partir desde a analectica dusseliana para compreender que a dominação erótica é um produto sociocultural na América Latina, dado que a conquista e a colonização deste continente trouxe como consequência novas formas de ser e estar neste território; até a apreensão de novos conceitos e premissas (a potência passiva aristotélica, o poder-ser dusseliano, o deixar ser ao ente levinasiano) para dilucidar a afirmação do ser que tem sido negado para chegar a compreendê-lo.

Palavras-chave: América Latina, mulher latino-americana, totalidadesistêmica, ser, alteridade, potência passiva, poder-ser, ente. 


\section{Situación actual de la mujer latinoamericana. El séptimo rostro de América Latina}

Inicialmente habría que aclarar que el primer criterio ético, según la filosofía de la liberación, es la vida. Así, una totalidad-sistémica que niegue la vida digna o la vida misma es injusta. De manera que se está ante un orden social injusto, prueba de ello es que pensar actualmente el ser de la mujer latinoamericana es un asunto vital, literalmente, puesto que la violencia de género es una cuestión no superada en América Latina. La vida de la mujer se arrebata con la pérdida de autonomía o se aniquila, por tal motivo no se le ha dejado ser, pues ha sido milenariamente negada como alteridad.

El oscuro panorama en el que es sumergido el lector dará cuenta que la reflexión sobre el ser de la mujer es necesaria e imprescindible, en la medida en que no se puede iniciar la solución a una problemática, sin antes comprenderla. Tiene razón T. Florence (2006) cuando menciona que la lucha de la mujer tiene que madurar y ser acompañada por un proceso sociocultural. Sin embargo, los triunfos de las mujeres no solo deben ser revisados bajo la luz de leyes y vocabularios incluyentes, pues resulta ser lo anterior un arma de doble filo, en tanto que los discursos se actualizan y aunque permitan la irrupción del Otro, no siempre es para reconocerlo, sino para subsumirlo en la totalidad, en términos dusselianos.

Entonces, basta con revisar la siguiente infografía, que realizó la Comisión Económica para América Latina y el Caribe (Cepal) el 16 de noviembre de 2015, en la que se evidencia cómo ser mujer en América Latina es una condición que puede llegar en algunos casos a ocasionar hasta la muerte.

Aunque en Colombia existe la Ley 1761, más conocida como Ley Rosa Elvira Cely, no se ha tratado a profundidad el tema de los feminicidios y la violencia en todas sus formas contra la mujer, puesto que el Centro de Referencia Nacional sobre Violencia de la Mujer (2015) dio a conocer en su informe Boletín epidemiológico las cifras de violencia contra la mujer entre enero y febrero de 2015. Este Boletín manifiesta que 126 mujeres han sido víctimas de homicidio; 2.631 acudieron al Instituto de Medicina Legal para ser valoradas por un presunto delito sexual; sobre la violencia intrafamiliar afirma que 735 niñas y mujeres adolescentes fueron víctimas de violencia por parte de un familiar o cuidador; 6.269 fueron víctimas de violencia de pareja. En cuanto 
a las mujeres mayores de 60 años, 119 de ellas fueron agredidas físicamente y 1482 fueron víctimas de violencia por parte de otros familiares.

Para comprender la problemática del ser y estar como mujer es menester no partir de la historia de las leyes en Colombia desde 1932 con la Ley 28 sobre el derecho de la mujer a administrar sus bienes, hasta 2015 con la Ley Rosa Elvira Cely; sino que habría que proponer en la reflexión teórica a la mujer como el séptimo rostro del pueblo oprimido de América Latina.

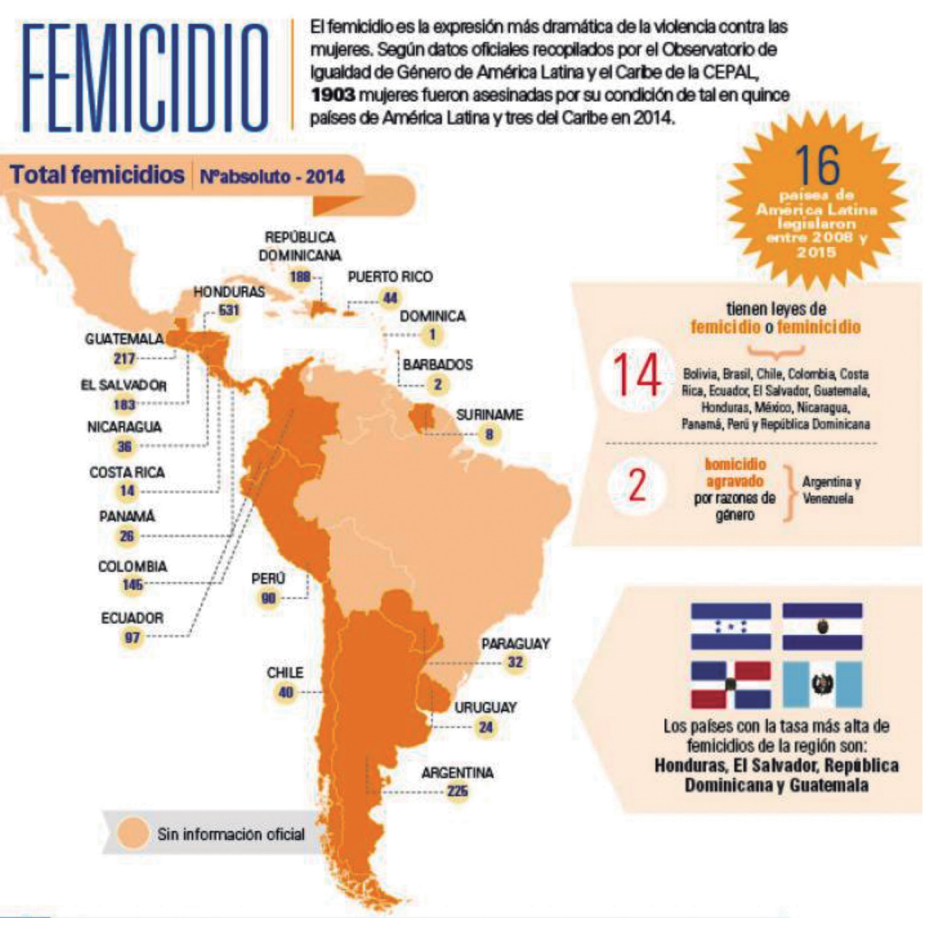

Fuente: Cepal (2015). Feminicidio. Recuperado de http://www.cepal.org/es/infografias/femicidio

Dussel (1992) reconoce seis rostros que se revelan en América Latina: el primero es el esclavo africano que fue comprado por los europeos, llevado a América y ahora es un afroamericano; el segundo es el indígena a pesar de la conquista y desaparición de los imperios inca, maya y azteca, otras tribus sobrevivientes de la conquista siguieron poblando América; el tercer rostro es representado por los mestizos, aquellos hijos de Cortés y de Malinche que quedaron en la ambigüedad, pues al no ser reconocidos 
por el padre y al no experimentar propiamente su cultura indígena quedan pues sin una identidad; el cuarto es el criollo, aquel que provoca generalmente los proyectos de emancipación del siglo xIx d.C. en América, puesto que el objetivo era dejar de ser colonias, pero para afirmar y monopolizar un Estado-nación en manos de los criollos; el quinto rostro se representa en los campesinos, indígenas, mulatos, zambos... que se dedican a trabajar la tierra y que, sin embargo, son víctimas de una oligarquía terrateniente y latifundista; y el último rostro que se exterioriza es el obrero que surge en la revolución industrial dependiente en el siglo xix d.C. en América Latina. Sin embargo, la mujer sufre desde 1492 una triple dominación, por ser mujer, por ser de una clase marginal, por ser latinoamericana. Esta triple dominación da lugar a la consideración de la mujer como el séptimo rostro de América Latina.

Cabe aclarar que la exclusión y la negación de las mujeres en América Latina no debe limitarse solamente a la situación de los feminicidios, ya que la vida no solo se aniquila, también se niega. Este primer apartado introductorio pretende ubicar al lector en la realidad de nuestro continente y país. Sin embargo, la reflexión teórica sobre la negación de la vida de la mujer latinoamericana es desarrollada desde los roles y funciones impuestos por las instituciones socioculturales que datan desde la conquista hasta nuestros días. Así en los campos erótico, político y pedagógico, la mujer tiene un modo de ser que le es asignado y que, por supuesto, niega su alteridad y su proyecto de vida, tal como se explicará en el siguiente apartado.

\section{Postulados para comprender el ser de la mujer según $\mathrm{E}$. Dussel}

Para transformar la condición de la mujer, es menester comprender a ese sujeto o ente, si se quiere, llamado mujer. Enrique Dussel (1998) inicia una reflexión filosófica sobre la experiencia del ser de la mujer, un tema álgido, complejo y aún no desarrollado a cabalidad, por tanto, hay que reconocer su aporte, en un primer momento. Pero también es necesario iniciar la retroalimentación de su propuesta.

Entonces, Dussel (1998) aborda la experiencia del ser de la mujer en tres momentos que responden a su método analéctico, puesto para dar lugar al Otro, a la Otra en este caso, se inicia con la negación, esto es, la descripción de la situación milenaria de opresión; luego, como segundo momento, continúa la negación de la negación, 
lo que trae como consecuencia la negación de la situación anterior; y finalmente la afirmación de la Otra, tercer momento.

\section{Negación}

La situación milenaria de opresión permite vislumbrar todo aquello que es en esta la mujer. Evidentemente, tal situación milenaria es fruto de las diferentes totalidadessistémicas históricas que han regido al mundo y que, traen consigo la negación de la alteridad. La mujer es víctima de una totalidad sin alteridad, por tanto, su ser está arraigado a la negación y la situación de opresión. Así, no es extraño que se la defina en cuatro formas alienadas que evidencian el ser de la mujer oprimida, como bien lo enuncia brevemente Dussel (1998), y de las cuales vale pena profundizar y así obtener un panorama holístico.

\section{Objeto primeramente sexual}

"La sexualización de la mujer en todas sus relaciones va a ser una manifestación de su opresión” (Dussel, 1988, p. 21). La mujer no es alguien, es un objeto cuya función radica en deleitar sexualmente a otra persona mediante sus atributos físicos. De manera que la mujer es vista no como un sujeto que desea, sino como un objeto que es deseado y que, a su vez, es deseado por partes (senos, cola, piernas, vientre, rostro).

De ahí que la actual totalidad-sistémica aprehenda al cuerpo de la mujer como mercancía para el consumo de otra mercancía. Lo anterior se ejemplifica con cualquier anuncio publicitario; si se quiere vender una moto es necesario mostrar a la modelo en bikini. Cabe mencionar que esta primera definición alienadora de la mujer como objeto sexual quedaría muchísimo más completa desde un punto de vista psicoanalítico, pues habrá que mencionar las pulsiones, goces y complejos que interactúan entre sí para que se dé un proceso de sexualización.

\section{Madre y educadora de los hijos}

Esta representación de la mujer ha sido concebida en todas las totalidades sistémicas desde el esclavismo, el feudalismo, hasta el capitalismo. Por tanto, el imaginario colectivo legitima que toda mujer deba tener como finalidad para su proyecto de vida el matrimonio, la maternidad y el vivir para la familia. De ahí que algunas mujeres feministas (S. Beauvoir, E. Goldman, T. Florece...) decidan no ser madres, puesto que 
no aceptan las condiciones socioculturales que permean las ideas y las implicaciones prácticas de la maternidad, así mismo, el rechazo de la determinación social de los roles frente a condiciones o posibilidades biológicas.

De lo anterior se podrían deducir dos elementos fundamentales y fundantes de la representación de la mujer como madre y educadora de los hijos; la primera radica en la negación ontológica de la mujer, puesto que el no-ser se encarna en la Otra (mujer) que no puede decidir de manera autónoma sobre su proyecto de vida, sino que por el contrario se le tiene un telos, una finalidad, un destino o una misión cuasidivina. Entonces, la mujer no-es, puesto que la negación a su proyecto de vida es, también, una negación a sus posibilidades de desarrollo en el mundo inmediato y sensible; la segunda deriva de la alienación en la que se somete al cuerpo femenino, ya que este se asume como ajeno, independiente de la mujer y como propiedad de otro que no es ella, incluso desde las condiciones biológicas y naturales. Basta con mencionar el tema del aborto, en el que se inmiscuyen los anteriores elementos, pues no importa el proyecto de la mujer, pues su destino es ser madre y el cuerpo ya no es suyo, aun cuando el padre no quiere responder o cuando el hombre responde, más no asume, como sí lo debe hacer la mujer, su rol paterno.

La mistificación de la mujer como mamá es un síntoma evidente de su alienación, no se puede negar lo increíble, bello y hasta fantástico que puede ser el cuerpo femenino que es capaz de dar a luz, dar vida, brindar alimento, ser abrigo y hogar durante nueve meses. No obstante, ser madre es una elección y no un destino, además de ser una decisión consensuada en la que el Otro (el hombre, mujer...) participa no solo en el acto sexual, sino también en la crianza y formación del hijo. Por tal motivo, la desmitificación de la maternidad influye en una nueva visión, pues si el padre y la madre comparten el proyecto de procrear, criar y formar, ¿no se estaría en una horizontalidad de roles donde ambos sujetos son activos debido a su participación?

\section{Ama de casa}

La tercera descripción de la situación milenaria de opresión, según Dussel, se encarna en la figura de dueña o señora de casa, en tanto que:

Se la deja ser poseedora de aquello que está cerrado, porque es la "casa”, mientras que la gran casa que es la sociedad económica, política cultural le está vedada, 
en gran parte. [...] El varón es el amo de todo, donde la casa es parte y pasa a veces a ser secundaria aún para él. (Dussel, 1988, p. 21)

Habría que evidenciar que el trabajo de la mujer no solo asalariado, sino que también su trabajo no remunerado en el hogar contribuye a la economía de la sociedad, en la medida en que sostiene el orden económico existente, puesto que su labor no remunerada en realidad representa millones en recursos para el producto interno bruto (PIB). Así mismo, el cuidado y manutención del hogar son la fuente de cubrimiento de las necesidades básicas del obrero (comer, descansar, tener una vida sexual activa...) y esto contribuye a que él pueda laborar como asalariado. Además, aunque la "gran casa" sea administrada por el hombre, la mujer contribuye en su crecimiento, pues:

Diariamente las mujeres aportan a este país [Colombia] solo por trabajo doméstico no remunerado 250 mil millones de pesos, ningún sector de la economía tiene este peso en el crecimiento del país, es decir, el 19\% de las cuentas nacionales. (...) Según datos oficiales el 90\% de las mujeres colombianas trabajan seis horas al día en labores domésticas no remuneradas, trabajo que sustenta el Producto Interno Bruto (PIB), pues aporta más de 120 millones de pesos diariamente. [...] Del 2001-2013, el país pasa de un crecimiento del PIB de $1,7 \%$ a $4,3 \%$ y en ese mismo período la brecha de género de la informidad creció el 5\%. (Semana, 2014)

De manera que el rol de la mujer con un trabajo no remunerado en la economía es crucial. Sin embargo, por condiciones socioculturales se acepta y se cree que la mujer debe hacerse cargo del hogar, así como también se profesa que el empleo de su tiempo en labores domésticas no es un trabajo, sino que es un deber. Tales nociones parece que nos transportarán al Neolítico, pues los roles del hombre y la mujer son similares, es como lo describió F. Engels (como se citó en Dussel, 1998):

El hombre va a la guerra, se dedica a la pesca y pone los medios necesarios para ello, así como la primera materia de la alimentación. La mujer cuida de la casa, de los alimentos y de los vestidos; guisa, hila y cose. Cada uno de los dos es el amo en sus dominios: el varón en la selva, la mujer en la casa. (p. 116) 


\section{La mujer es por mediación del varón}

Esto quiere decir que si el hombre se realiza ella también, Dussel (1998) denuncia muy brevemente dos ejemplos cotidianos de tal mediación; primero, en el lenguaje "el ser es lo unívocamente masculino, la especie humana es el hombre” (Dussel, 1998, p. 21), por tanto, la mujer queda representada como un momento secundario, dependiente y adyacente del hombre. Esto es así en la medida en que el lenguaje - entendiendo por este, un acto comunicativo basado en un sistema de signos- es abarcado por el sexo masculino y representa a los géneros.

T. Florence (2006), para argumentar la propuesta de la necesidad de un lenguaje incluyente, muestra cómo cuando se busca en el Diccionario de la Real Academia la palabra hombre aparecen 67 términos, 37 laudatorios, 23 neutros y siete denigrantes, en todas concuerda la connotación de hombre como especie humana; mientras que la palabra mujer tiene solo 12 referencias, dos laudatorias, una neutra, nueve denigrantes (prostituta), en todas aparece la connotación sexual biológica-hembra. Concuerdan Dussel (1998) y Florence (2006) en que la mujer se ha representado por mediación del varón en el lenguaje.

El otro ejemplo del filósofo argentino era sobre la manera en la que se empleaba en el nombre de la mujer el primer apellido del esposo, entonces se decía Diana Díaz de, seguía el apellido del cónyuge, manifestaba Dussel, "ese 'de’ muestra la alienación, esa alienación aún jurídica de la mujer” (Dussel, 1998, p. 22). Y es que ese de, en efecto, señala una propiedad privada, un algo que le pertenece a alguien. En Colombia solo hasta el año 1970 con el decreto 1260 se declara el uso no obligatorio del apellido del cónyuge, no obstante, hay parejas que mantienen ese de que hace referencia a una relación de propiedad.

Ante los cuatro factores nombrados anteriormente sobre la opresión de la mujer, concluye Dussel (1988) que hay dos respuestas de la mujer, no obstante estas surgen desde su negación y subsunción a una totalidad-sistémica falocrática; la primera consiste en mistificar su propia alienación, esto conlleva sublimar la debilidad, la belleza, "de tal manera que hay una mistificación de la femineidad que nos permite ver realmente lo que encubre la cuestión” (Dussel, 1998, p. 22). La segunda respuesta de la mujer es aquello que Freire (2005) manifestó como introyección del opresor en el oprimido y en lo que Dussel concuerda al manifestar que se produce una introyección por medio de la pedagogía domesticadora del opresor, así que: 
Desde la más tierna infancia, nosotros empezamos a pre-determinar a esta doble funcionalidad social, histórica y política, unos a ser domesticadores y otros a ser dominados. Vamos a ver cómo la mujer oprimida va a educar a su hijo varón como el señor que ella no fue, y a su hija mujer como la oprimida que ella es; de tal manera que los va a educar contra su propia conciencia, quizá justamente como no quería. (Dussel, 1998, p. 23)

En este orden de ideas, la experiencia del ser de la mujer tiene hasta este punto un carácter negativo, en tanto que las cuatro formas de representación de la mujer responden a la alienación en la que se encuentra y frente a estas la respuesta fáctica es seguir perpetuando el rol que se le ha asignado desde la totalidad falocrática. De ahí que, el paso a seguir sea la negación de todo lo visto, esto es, el ser de la mujer oprimida.

\section{Negación de la negación}

Respecto a la situación anterior (visualización del ser de la mujer oprimida) E. Dussel realiza una crítica ética, esto es, meta-física, puesto que el punto de partida para negar la negación de la mujer, como Otra, es partir de ella y no del hombre que se ha establecido como el ser de la totalidad-sistémica. Por tal motivo,

Es la sociedad total la que es injusta y es una sociedad totalitaria la que no permite la irrupción "del Otro" como otro, porque el Otro me puede increpar sus exigencias de justicia. Si “al Otro" lo tengo "metido" dentro del Todo nada sabe de su opresión. (Dussel, 1988, p. 23)

De manera que la negación de la situación anterior está enmarcada por la apertura a la Otra en términos éticos y, a su vez, esta apertura es Justicia, porque la Otra interpela y exige la superación de una totalidad egoísta, que la ha negado como alteridad y la ha alineado para que nada sepa de su opresión. No obstante, advierte Dussel (1998) en América Latina los grupos dominadores han heredado la erótica de los conquistadores, burócratas hispánicos, criollos encomenderos, oligarquías nacionales $y$ europeas, lo que trae como consecuencia que la dominación erótica sea también una dominación del hombre sobre el hombre, pues: 
La clase dominante dispone de un principio de realidad que le sirve para mantenerse en el poder. Este principio de realidad es dominación erótica —como después lo será también como dominación pedagógica y política一. Es necesario no olvidar que la costumbre de opresión sexual del varón dominador sobre la mujer de su clase y como profanación de la mujer de la clase oprimida socio-políticamente, es un momento esencial de la dominación del hombre: la falocracia es un momento de la plutocracia. (Dussel, 1998, p. 115)

Por lo que la institución aparentemente monogámica (en el campo erótico) posee los roles de represor y reprimido. Pero también se ejerce la doble moral que afecta más que todo a la mujer, ya que se crea una moral sexual cultural — como Dussel (1998) lo retoma de Freud- que trata de establecerse como una moral sexual natural, de manera que no se pueda censurar aquello que ha sido aprobado y legitimado socialmente, aunque sea fruto de la dominación de los que detentan el poder. Por tanto, no se debe confundir lo cultural con lo natural, en la medida en que hay normas sociales vigentes que fomentan la dominación del hombre sobre el hombre, en este caso puntual de la sociedad sobre la mujer, que de ninguna manera son naturales, porque son fruto de las relaciones sociales. De igual manera, las condiciones biológicas naturales no son determinantes sociales.

En vista de lo anterior y a modo de crítica, Dussel (1998) enuncia el êthos de la dominación erótica, este trae consigo un fundamento que radica en la falta de dominio sobre sí mismo a causa de la esclavitud producto de la pulsión totalizante. Esta pulsión consiste en eliminar al Otro como otro y determinarlo como lo Mismo.

Así mismo, atina Dussel en deducir que la alteridad del Otro-clitoriano-vaginal es constituida como no-falo, por ello queda establecida como un momento negativo en la totalidad fálica y autoerótica, la sexualidad del Otro como dis-tintamente sexuado es negada. En consecuencia:

Alienación de la mujer significa el no respetar su dis-tinción sexual, la manera clitoriana-vaginal de abrirse originariamente al mundo. Alienación de la mujer es comprenderla como falicidad castrada o como ob-jeto fálico. [...] El mal sexual no significa ejercicio erótico dual (varón-mujer), sino totalización fálica de la sexualidad. (Dussel, 1998, p. 123) 
Por tanto, manifiesta Dussel (1998) que "la liberación de la mujer no se va a dar solo por la mujer, sino va a ser la liberación integral del hombre" (p. 23). En la medida en que el hombre es víctima también de una totalidad que le ha impuesto unos determinados hábitos represores (no es de un hombre llorar, hacer los quehaceres, jugar con muñecas, etc.) y, a su vez, le ha asignado el papel de Ego dominans en la relación erótica, política y pedagógica frente a la mujer.

Sin embargo, la alineación de la mujer pasa por un plano ontológico que justifica la praxis de dominación en todos los campos. Incidentalmente debido a la conquista, la mujer latinoamericana desde su exterioridad es víctima de la totalidad europea conquistadora que irrespeta su alteridad, su corporalidad en una dimensión sexual, lo que trae como consecuencia esta dominación erótica:

La alienación ontológica de la mujer europea viene a multiplicarse en América Latina, porque el ego por sí dominador eróticamente en Europa viene ante nosotros a reduplicarse como ego imperial. A la dependencia de nuestra cultura como tal se agrega la moral cultural de opresión de la mujer. La erótica queda legalmente y según las costumbres desquiciada en su esencia, pero justificada ontológicamente. (p. 116)

Entonces, la negación de la negación es en pro de la apertura a la Otra, implica el respeto por su libertad. "Libertad no es aquí solo una cierta posibilidad de elegir entre diversas mediaciones que penden del proyecto cotidiano. Libertad es ahora la incondicionalidad del Otro con respecto al mundo en el que siempre se es centro" (Dussel, 2011, p. 84). A causa de esto, la negación de la situación anterior (ser de la mujer oprimida) da a lugar al cambio de representación que se ha atenido de la Otra como mujer (ama de casa, objeto sexual, realización por medio del hombre y rol exclusivo de madre y educadora de los hijos) para afirmar que ella tiene un proyecto de vida en el que elige sus mediaciones, pero también su incondicionalidad en el mundo en la que siempre es centro.

Acto seguido, de la negación de la negación es la afirmación, a causa de esto esta descripción tiene en sí elementos de afirmación. Sin embargo, es menester aclarar que tal afirmación supone pasar del no-ser al ser, es decir, de la negación al reconocimiento y enunciación de las posibilidades de ser en el mundo fácticamente, en el 
caso de la mujer, ser no como oprimida, ni como opresora, sino ser desde su plena libertad y alteridad.

\section{Afirmación}

Cabe mencionar, es en este punto del presente trabajo que se está ante el talón de Aquiles de la filosofía de la liberación de E. Dussel, puesto que el filósofo en su condición contempla el ser de la mujer desde su horizonte, esto es, desde su marco categorial, método y su condición sexo genérica masculina, sin embargo, de manera honesta y responsable enuncia en 1977:

Creo que estamos tan mal situados, que desde ya debo indicar que pienso que no puede ser hoy adecuada y correctamente respondida, existencialmente y en verdad, la pregunta que interroga por el ser de la mujer ¿Por qué? Porque está tan oprimida y tan introyectada su opresión y en mí mismo, que escribo esto, está de tal manera introyectada mi propia alienación en la mujer, que correría el riesgo de darles una solución que solo sería encubridora. De tal manera que, sabiendo la respuesta por la pregunta por el ser de la mujer es hoy todavía imposible, pues el camino de la liberación casi no ha comenzado, sin embrago querría indicar ciertas pistas y sobre todo cerrar ciertos caminos, de tal manera que no es repuesta, sino un cuestionamiento de la misma pregunta. (Dussel, 1998, p. 29)

Aun así diecisiete años después, en 1994, escribe Dussel un epílogo a la edición de Liberación de la mujer y erótica latinoamericana en la que nuevamente expone unas pautas para seguir reflexionando sobre el ser de la mujer. Entonces parece pertinente retomar lo dicho por E. Dussel y sobre estas aclaraciones emprender la deliberación filosófica sobre el tema que convoca el ser de la mujer latinoamericana.

Por el hecho de que, la filosofía de la liberación re-toma y re-fundamenta el planteamiento de la alteridad, la pregunta por el ser no conduce directamente al campo ontológico, aunque se vuelva la mirada crítica a este para enunciar una praxis desde Occidente, puesto que "la liberación es el movimiento mismo meta-físico o transontológico por el que se traspasa el horizonte del mundo. Es el acto que abre la brecha, que perfora el muro y se adentra en la exterioridad insospechada, futura, 
nueva en realidad" (Dussel, 2011, p. 108). El cuestionamiento por el ser traslada a quien se pregunte al campo meta-físico, a causa de esto no es de extrañar que Dussel comience su disertación, en la que indica ciertas pistas, por una conceptualización de la metafísica de la femineidad, así parece que quiere dilucidar lo natural y lo cultural para reflexionar sobre esto sin equívocos.

Por una parte, E. Dussel (1998) aclara qué se debe entender por femineidad, esto es, primero, no se debe confundir persona humana con femineidad, ya que la mujer es persona humana al igual que el varón (en términos dusselianos de los setenta); segundo, la mujer es portadora exclusiva de la femineidad, aunque no la única, puesto que el varón también tiene notas de femineidad, de la misma manera, que ella tendrá notas de masculinidad. El punto clave es, según Dussel, comprender cómo el varón y la mujer portan notas distintivas. La pregunta es “¿en qué plano la mujer es mujer y el varón es varón?” (Dussel, 1998, p. 30).

Por supuesto tal cuestionamiento no surge porque sí, sino que por el contrario es fruto de una reflexión crítica de Dussel (1998) frente a la propuesta inicial de los feminismos extremos en el siglo XIX, ya que estos planeaban la igualdad de la mujer desde la indiferenciación de la distinción de sexos; basta analizar la praxis de las feministas francesas en el siglo $\mathrm{xx}$, las mujeres feministas se vestían como hombres para ser no solo tratadas igual que ellos, sino concebidas como ellos. El problema de esto es que no existe como tal un reconocimiento por la Otra, sino que la mujer es identificada como lo Mismo dentro de la totalidad falocrática. Por tanto, "la liberación erótica lleva entonces a permitir al Otro ser otro sexualmente dis-tinto y poder vivir la plenitud alterativa de la sexualidad humana" (Dussel, 1998, p. 123). La pregunta por el plano de la mujer y del hombre defiende la idea de que la liberación erótica es posible partiendo de la dis-tinción sexual y no de la indiferenciación sexual. Es menester dilucidar que la distinción sexual no conlleva la afirmación de que es imposible la coexistencia entre los géneros como lo planeta el feminismo separatista.

Por otra parte, en Dussel, la femineidad debe entenderse como una noción que tiene doble referencia (relación bipolar) y, a su vez, es dialéctica (campos dusselianos). Entonces, la mujer se referencia por su distinción frente a la masculinidad, esta referencia se debe a que siempre se va a encontrar como sujeto (sea hombre o mujer) en los campos erótico, político y pedagógico lo distintamente sexuado. 
Sería menester para clarificar este punto ver la figura que representa un esquema hecho por Dussel, pues en esta se refleja la dualidad referencial: varón-mujer, en los campos en los que se desarrolla la vida misma. Al mismo tiempo, se entiende cómo Dussel organiza los campos según su función antropológica y la intensidad (mayor, menor y mínima) de la distinción sexual de roles en la sociedad.

Figura 2. Esquema dusseliano sobre la persona humana.

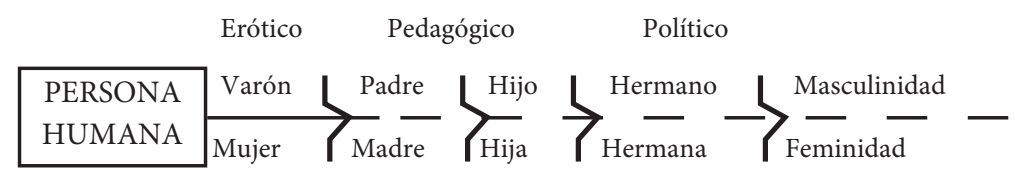

Mayor > menor > mínima

Fuente: Dussel, E. (1998). Liberación de la mujer y Erótica latinoamericana. (p.31). Bogotá: Nueva América.

Dada la triple dialéctica dusseliana, la mujer y el hombre quedan como iguales, en tanto que, personas humanas. Sin embargo, la distinción entre varón y mujer por su sexualidad es mayor en el campo erótico, porque queda definida - al igual que le acontece al hombre- como eróticamente sexuada, es una exterioridad clitoriana-vaginal y no un no-falo; en el campo pedagógico, pese a que la mujer en la maternidad biológica matiza la distinción frente al varón, esta disminuye, ya que frente a la educación y el hogar tanto el hombre como la mujer comparten y participan activamente, por tanto la distinción masculinidad-femineidad es menor; a diferencia de los campos anteriores, para Dussel en el campo político la distinción es nula, más no negada, puesto que si se basa el trabajo por rasgos sexuales se caería nuevamente en la división sexual del trabajo, en la explotación y la dominación de un género sobre otro.

Cabe hacer la salvedad que en 1994 Dussel reconoce que esta diferenciación sexual, que pasa desde un plano socio-económico y político, debe plantearse ahora bajo la categoría de género pasando por dimensiones psíquicas y biológicas de la sexualidad. Entonces, como aporte de forma podría colocarse en la figura anterior persona humana seguido de género, en vez de varón y mujer. Pero en contenido, las distinciones sexuales propias de la esencia que puedan llegar a tener los géneros también cumplen el orden allí establecido, pues ¿qué sentido tendría seguir perpetuando diferencias sociales y políticas por el hecho de ser de un género determinado? ¿Se es mejor o peor senador por ser homosexual, pansexual, transexual, bisexual? ¿Si se elimina 
la distinción sexual en la erótica no volveríamos a una totalidad concebida bajo un solo sexo? No obstante, este trabajo se centra en la mujer, pero no por ello puede desconocerse la importancia, como bien lo dice Dussel, de integrar esta reflexión desde el género.

Para finalizar este apartado, son seis las conclusiones a las que llega E. Dussel después de un análisis a la metafísica de la femineidad en la que la persona humana no es exclusivamente el hombre, como tampoco la femineidad necesariamente debe identificarse con mujer; la primera conclusión manifiesta que "la liberación de la mujer es la liberación del hombre como especie" (Dussel, 1998, p. 32), debido a que solo en un orden más justo se establecerá la liberación de la especie humana en cuanto tal; segunda conclusión, la mujer porta femineidad en el nivel sexuado erótico, igual que el hombre porta masculinidad en el mismo nivel, pero el asunto radica en identificar los matices de las diferencias y las igualdades en la distinción; tercera, "la mujer, persona humana, porta la femineidad esencialmente en su nivel sexuado en la maternidad" (Dussel, 1998, p. 32). No obstante, Dussel (2014) reconoce que la función de la mujer no es la maternidad, pero ella es capaz de dar vida; cuarta conclusión la mujer en tanto portadora de femineidad no tiene diferencia en el campo pedagógico, puesto que la educación en el sistema pedagógico erótico, como también en el sistema pedagógico político no es una cuestión de género (para actualizar los términos); la quinta, la mujer como portadora de femineidad no tiene tanta diferencia en su función de trabajo y política; la última conclusión, la mujer como ama de casa refleja una oprimida social y política, por lo que en los trabajos domésticos ya no debe existir diferencias por distinción sexual.

\section{Retos y premisas para una aproximación de la definición del ser mujer desde el campo meta-físico}

\section{Meta-física de la alteridad: abordar al ente a partir del ser, es, a la vez, dejarlo ser y comprenderlo}

Para tratar de responder a la pregunta por el ser de la mujer fue menester revisar algunas propuestas filosóficas occidentales en torno a la reflexión del ser y el sujeto, estas demostraron cómo desde los orígenes de la Metafísica hasta el siglo xx los planteamientos tuvieron una autonomía relativa, en tanto que estaban no solo determinados, sino también condicionados por el contexto histórico y cultural desde el que se pensaba. 
Así, la pregunta por el ser desde Aristóteles, Tomás de Aquino, la línea del Ego cogito y de la Voluntad de poder, era enunciada desde un sujeto masculino que, o bien no reconoció que más allá del Yo estaba la Otra, o aprehendió a la Otra para negarla y subsumirla dentro de lo Mismo. A causa de esto, los postulados occidentales durante el período de la Modernidad constituyeron que "el sujeto europeo que comienza por ser un 'yo conquisto' [1492] y culmina en la 'Voluntad de Poder' es un sujeto masculino. El Ego cogito es el Ego de un varón” (Dussel, 1998, p. 37). Entonces es la metafísica la expresión de la meditación del sujeto moderno sobre sí mismo y posteriormente, hasta la acción de ese sujeto es interpretada en relación con los apetitos, pasiones e instintos.

En contraste con el anterior proyecto, aparece la perspectiva de la eta-física de la alteridad (ética) fundamentada por E. Lévinas y retroalimentada por E. Dussel, esta meta-física inicia su reflexión desde la exterioridad del Otro, lo que trae como consecuencia entender que más allá del ser está el Otro. Así, en primer lugar, valdría la pena retornar y retomar la afirmación de E. Lévinas sobre la relación del ente y el ser: “abordar al ente a partir del ser, es, a la vez, dejarlo ser y comprenderlo" (Lévinas, 1977, p. 69). Entonces, la relación con el Otro, con el ente, va a determinar la compresión del ser, pues es el Otro quien detenta el ser.

La relación con ente, según Lévinas (1977), no es pues de apresamiento o neutralización, por ello manifiesta que se debe dejar ser al Otro, de esta manera la Metafísica recibe al Otro desde su exterioridad. Si tal aseveración es correcta, valdría la pena pensar si al ente llamado mujer se lo ha dejado ser, ya que de ser así bastaría iniciar con la apertura del ser de la Otra. Sin embargo, como los seres humanos realizan la historia, habría que buscar en la misma el desarrollo de las posibilidades fácticas para la compresión del ser del ente denominado mujer, o por lo menos develar si se le ha permitido ser. Por tanto, habrá que leer este fragmento de Patas arriba: la escuela del mundo al revés de E. Galeano para entender la relación con el ente llamado mujer:

Son cosas de mujeres, se dice también. El racismo y el machismo beben en las mismas fuentes y escupen palabras parecidas. [...] Los inquisidores dedicaron todo el manual, desde la primera hasta la última página, a justificar el castigo de la mujer y a demostrar su inferioridad biológica. Ya las mujeres habían sido largamente maltratadas por la Biblia y por la mitología griega, desde los tiempos 
en que la tonta de Eva hizo que Dios nos echara del Paraíso y la atolondrada de Pandora destapó la caja que llenó al mundo de desgracias. "La cabeza de la mujer es el hombre", había explicado San Pablo a los corintios, y diecinueve siglos después Gustave Le Bon, uno de los fundadores de la psicología social, pudo comprobar que una mujer inteligente es tan rara como un gorila de dos cabezas. Charles Darwin reconocía algunas virtudes femeninas, como la intuición, pero eran "virtudes características de las razas inferiores".

[...] [En] la historia oficial de las Américas [...] mucho menos se habla de las indias y de las negras que encabezaron algunas de las muchas rebeliones de la era colonial. Ésas son las invisibles; por milagro aparecen, muy de vez en cuando, escarbando mucho.

[...] No hay tradición cultural que no justifique el monopolio masculino de las armas y de la palabra [...] en la mitología campesina latinoamericana son casi siempre fantasmas de mujeres, en busca de venganza, las temibles ánimas, las luces malas, que por las noches acechan a los caminantes. En la vigilia y en el sueño, se delata el pánico masculino ante la posible invasión femenina de los vedados territorios del placer y del poder; y así ha sido desde los siglos de los siglos.

Por algo fueron mujeres las víctimas de las cacerías de brujas, y no solo en los tiempos de la Inquisición. Endemoniadas: espasmos y aullidos, quizás orgasmos, y para colmo de escándalo, orgasmos múltiples. [...] La envidia y el pánico ante el placer femenino no tenían nada de nuevo. Uno de los mitos más antiguos y universales, común a muchas culturas de muchos tiempos y de diversos lugares, es el mito de la vulva dentada, el sexo de la hembra como boca llena de dientes, insaciable boca de piraña que se alimenta de carne de machos. Y en este mundo de hoy, en este fin de siglo, hay ciento veinte millones de mujeres mutiladas del clítoris. (Galeano, 2000, pp. 53-54)

Después de todo, parece ser que ese rastreo histórico con la delicadeza y cuidado del lenguaje literario de E. Galeano evidencia que el ente mujer desde la historia — que no es cualquier cosa, ya que refle las acciones de los seres humanos en el tiempo- no se ha podido comprender, porque no se le ha dejado ser y esto es de suma importancia para pensar en el ser de la mujer, pues "la metafísica se desenvuelve ahí donde se desenvuelve la relación social: en nuestra relación con los hombres” (Lévinas, 1977, p. 101). 
A pesar de haber sintetizado los aportes teóricos de E. Dussel parece necesario retroalimentar la propuesta dusseliana, en la medida en que la reflexión del ser de la mujer latinoamericana no puede ser aún elucidada en su totalidad, debido a la negación sociocultural que ha tenido la mujer a lo lago de la historia, por ello para poder comprender en un futuro el ser de la mujer se debe ampliar el marco categorial metafísico que posibilite dilucidar la afirmación de su ser. Por ello, propongo utilizar no solo las categorías dusselianas tales como alteridad, exterioridad, totalidad-sistémica, alienación o subsunción, proximidad y liberación, sino también aprehender dos categorías (potencia pasiva aristotélica y poder-ser dusseliano) y el postulado levinasiano "abordar al ente a partir del ser, es, a la vez, dejarlo ser y comprenderlo".

\section{El ser de la mujer como potencia pasiva aristotélica}

Aunque al ente mujer no se le haya dejado ser, esto no quiere decir que no sea, pues es en tanto persona humana. Por ello, habría que mencionar los planteamientos aristotélicos, no sobre el orden jerárquico en el que la mujer queda subyugada al hombre, sino el sentido del ser como acto y potencia.

En este orden de ideas, cabría considerar a la mujer como potencia pasiva, entendiendo que "está, en efecto, la potencia pasiva la cual se da en el sujeto afectado, y es el principio del cambio pasivo por la acción de otro, o de (ello mismo, pero) en tanto que otro" (Met. Libro IX, 1046 a-1015). Por ende, se establece la potencia pasiva, debido a que el sujeto que es afectado por la acción del otro.

Lo anterior es bastante interesante y digno de reflexión, en tanto que, como bien lo enunció Dussel (1998), las representaciones de la experiencia del ser de la mujer desde su situación de opresión (ama de casa, objeto sexual, realización por medio del hombre y rol exclusivo de madre y educadora de los hijos) indican esa afección por la cual solo a través de la acción del hombre se da un cambio. Pero este cambio se debe entender desde la pasividad, por tanto la afección no provocará en la potencia la plena realización, pues su condición de pasivo no permite la conversión en acto.

De igual importancia, "todo agente capaz de actuar de acuerdo con la razón hará necesariamente, cuando lo desee, aquello para lo cual tiene capacidad, y en el mismo que la tiene" (Met. Libro IX, 1048 a-15). La potencia pasiva no actúa sobre la potencia activa, según Aristóteles, el dominio corresponde al deseo o la elección, mientras que 
lo pasivo no tiene la capacidad de deseo o elección. Esto, sin lugar a dudas, evoca un pasaje sobre la erótica hispanoamericana, a diferencia del hombre conquistador que era una potencia activa, es decir, realizada, la mujer amerindia no era una potencia activa, entonces no tenía la capacidad de deseo u elección.

En este orden de ideas, la mujer latinoamericana sobre la que versa este trabajo queda establecida en la práctica no-ser por su condición de oprimida, latinoamericana y mujer, y, en teoría, como potencia pasiva. De ahí que son tres los momentos fundantes para la praxis de la concepción fálica y falocrática en América Latina; lo anterior queda constituido en la erótica simbólica, la erótica hispanoamericana y la erótica latinoamericana la mujer desarrollada por Dussel (1998). La sexualidad, en este punto, también es desarrollada por un varón que concibe a la mujer como pasividad, pues es - como en toda sociedad falocrática-, para decirlo en términos de Freud, el albergue del pene del conquistador, del guerrero europeo, del mercenario, es un objeto más para dominar.

De igual importancia es comprender que la dominación erótica es un producto sociocultural en América Latina, puesto que la conquista y la colonización de este continente trajo como consecuencia nuevas formas de ser y estar en este territorio, en la medida en que, con la pérdida y negación de las culturas amerindias e incorporación a la totalidad-sistémica europea, llevó a América a un nuevo proceso social, cultural, económico y político que versa sobre el dominio del hombre sobre el hombre, pero también de un género sobre otro. Lo que trae como consecuencia establecer en primera instancia que la mujer latinoamericana no es potencia que tiende a la realización, sino que es una potencia pasiva que solo tiende al cambio debido a las potencias activas que se desarrollan en una totalidad falocrática.

\section{Poder-ser dusseliano}

Si acierta Dussel (1987) sobre el planteamiento de la comprensión existencial como estructura que piensa la ética y en tanto que la ética es meta-física, entonces para abrirse al mundo es necesario des-cubrir los entes que ya son en él. No obstante:

El hombre tiene un poder-ser (que no por ello deja de ser dynamis en el sentido aristotélico óntico o real) que es asumido en el horizonte ontológico, y en este nivel al que el hombre se abre en exclusividad, la dynamis óntica se convierte en el poder-ser de una finitud mundana que se des-vive por lo que le pre-ocupa; 
su ser que le ad-viene como poder-ser. Se abre así a sus pies un abismo: entre su ser ya-dado fá-cticamente y su poder-ser, y queda como en medio de dos bordes de un precipicio nunca franqueable. (Dussel, 1987, p. 57)

En este orden de ideas, la mujer latinoamericana es - al igual que las mujeres de los demás continentes-potencia pasiva, mientras se siga en una totalidad falocrática o en ese patriarcalismo milenario. De ahí que se vea la necesidad de complementar tal modo de ser con el contexto histórico-socio cultural de América Latina, puesto que así se comprende que el ser otorgado a la mujer o, en palabras de Dussel, el ser ya-dado fácticamente, responde a una lógica de alienación. Cabe mencionar nuevamente que por estas dinámicas no se conoce el ser de la mujer, pues no se la ha dejado ser libremente.

Ahora bien, si se quiere realmente la plena realización de la mujer, pasar a ser acto, habría que garantizar su poder-ser, puesto que este refleja la transcendencia del sí mismo hacia la facticidad, según Dussel. De manera que, y siguiendo los postulados de la filosofía de la liberación, el poder-ser implica un proyecto fáctico, pues "el hombre no tiene una com-prensión estática de sí mismo, sino ex-tática; nunca termina de comprenderse en un último-horizonte-ya-dado" (Dussel, 1987, p. 59).

Es por lo dicho anteriormente que acierta la filosofía de la liberación en postular al campo político como condicionante y condicionado de los demás campos (erótico y pedagógico), pues si la mujer aspira a realizarse en acto, en poder-ser de acuerdo con su proyecto de vida, deberá reconocer la importancia de la transformación del campo político, puesto que allí se encuentra toda la acción humana social práctica (Dussel, 2011). Así pues, es el campo político donde se postula como proyecto el ser del sistema, hasta el momento ha sido "el ser es, el no-ser no es", es decir, la negación de la alteridad. Esta negación será perpetuada por las acciones de la especie humana que le dan contenido a ese enunciado, tal como aconteció en la conquista y luego se teorizó desde el Ego cogito hasta la voluntad de poder. Entonces, la mujer latinoamericana debe asumir su alteridad negada desde el campo político principalmente e iniciar la apropiación del proyecto sistémico y, a su vez, efectuar el poder-ser que no ha sido, ni ella como latinoamericana ni América Latina, continente dependiente y oprimido.

De manera que la política también puede entenderse como el sistema de sistemas institucionales, por lo cual se decía que era condicionante-condicionada, por tanto 
como cada campo está interconectado e interrelacionado con lo demás, la fetichización de uno puede corromper el resto, es por ello que la lucha de la mujer no puede quedarse como reivindicación aislada de las condiciones sociales y económicas, ni mucho menos de los otros rostros que igual que ella sufren la dominación del hombre sobre el hombre.

La mujer - igual que los otros rostros que viven en una situación de opresión - debe ser consciente no solo de sí misma, sino también del lugar que ocupa en la totalidadsistémica para efectuar una posible acción que trascienda y vaya más allá de un interés individual o particular, entendiendo este como la primacía exclusiva de intereses y reivindicaciones femeninas, sino que se integre a los demás rostros, sujetos, alteridades negadas que pueblan América Latina y reafirme su posición como alteridad que se disputa como poder-ser y querer ser desde su otredad.

\section{Conclusiones}

Para finalizar, solo es posible comprender el ser de la mujer latinoamericana superando la negación del ser del ente que ella es. Lo anterior se clarifica con la negación ontológica y la subsunción a la que se enfrenta la mujer tanto teóricamente, con los sistemas de pensamiento occidentales, como prácticamente con la invasión a América en 1492 y el surgimiento del sujeto latinoamericano. Así pues, aunque la Totalidadsistémica le ha otorgado un ser-dado-fácticamente, en tanto que, la experiencia del ser de la mujer está dada desde su situación de opresión: como ama de casa, objeto sexual, realización por medio del hombre y rol exclusivo de madre y educadora de los hijos; esta investigación esboza algunas premisas metafísicas transversales para comprender el ser de la mujer latinoamericana (potencia pasiva, dejar ser al ente para comprender el ser, poder-ser).

Ahora bien, el aporte de E. Dussel a la problemática del ser de la mujer es clave, ya que la fusión de los campos dialécticos (político, erótico, pedagógico) con el marco categorial de la filosofía de la liberación y el método analéctico permitieron estudiar los momentos de negación de la alteridad, que pasa por la experiencia del ser de la mujer oprimida; negación de condición de la negación de la alteridad, que no es otra cosa que la desmitificación de ese ser oprimido; la afirmación de la alteridad misma, en la que Dussel reconoce no poder dar una respuesta acertada por su condición de 
hombre contaminado por la cultura machista, pero esboza postulados recogidos de lo que no es la mujer.

La reflexión filosófica dusseliana previene cómo no se debe confundir lo cultural con lo natural, en la medida en que hay normas sociales vigentes que fomentan la dominación del hombre sobre el hombre, en este caso puntual de la sociedad sobre la mujer, que de ninguna manera son naturales, porque son fruto de las relaciones sociales. De igual manera, las condiciones biológicas naturales no son determinantes sociales.

La riqueza de pensar desde la filosofía de la liberación la problemática del ser de la mujer latinoamericana giró en torno a la afirmación de la alteridad y de la exterioridad de una mujer que nace en un territorio que constituyeron como lo "Mismo", pero que se quiere Otro. Además de la reivindicación no de la indiferenciación sexual, sino del derecho de ser y estar en los campos político, pedagógico y erótico en los que se desarrolla la vida como Otro distintamente sexuado.

Acierta Dussel en que la liberación de la mujer debe empezar por el campo erótico, asimismo el reflejo de esta dominación es producto de la dominación del hombre sobre el hombre, por tal motivo faltaría ampliar la reflexión sobre las mediaciones que en el campo político darán lugar también a la praxis liberadora de la mujer latinoamericana. Lo anterior no es para perpetuar "el ser es, el no-ser no es", sino, por el contrario, para permitir que el otro negado y subsumido sea eficazmente, sea realmente como plena realización.

No obstante, lo investigado en este trabajo permitió una concepción desde la liberación de la mujer que pasa indudablemente por el reconocimiento y el dejar ser de la alteridad que ella es. Sin embargo, no es de ninguna manera una visión negativa o reduccionista de la alteridad, en tanto que, asumirse como Otro no es plantearse como lo inesencial o secundario, por el contrario, es afirmarse como persona humana digna de reconocimiento, respeto y sobre todo como alteridad que siempre interpela justicia.

Es correcto manifestar que "la metafísica se desenvuelve ahí donde se desenvuelve la relación social: en nuestra relación con los hombres" (Lévinas, 1977, p. 101), por tal motivo la liberación de la mujer debe partir de una reflexión trans-ontológica, que se instaura en la meta-física (ética) que denuncia un orden éticamente injusto, en tanto que niega la posibilidad de ser y estar como Otro, distinto. 


\section{Referencias}

Aristóteles. (1994). La metafísica. Tomás Calvo Martínez (Trad.) Madrid: Gredos.

Cepal (2015). Feminicidio. Recuperado de http://www.cepal.org/es/infografias/femicidiohttp://www.cepal.org/es/infografias/femicidio

Dussel, E. (1987). Filosofía ética de la liberación. Tomo I, Presupuestos de una filosofía de la liberación. Buenos Aires: La Aurora.

Dussel, E. (1992). 1492: el en-cubrimiento del Otro. Bogotá: Ántropos.

Dussel, E. (1998). Liberación de la mujer y erótica latinoamericana. Bogotá: Nueva América.

Dussel, E. (2011). Filosofía de la liberación. México: Fondo de Cultura Económica.

Florence, T. (2006). Conversaciones con Violeta. Historia de una revolución inacabada. Buenos Aires: Aguilar.

Galeano, E. (2000). Patas arriba la escuela del mundo al revés. Madrid: Siglo XXI.

Instituto Nacional de Medicina Legal y Ciencias Forenses. (Marzo 6 de 2015). Boletín epidemiológico. Información estadística de violencia contra la mujer. Recuperado de http://www.medicinalegal.gov.co/el-instituto/-/asset_publisher/4Of1Zx8ChtVP/ content/cifras-estadisticas-de-violencia-contra-la-mujer-en-2015

Lévinas, E. (1977). Totalidad e infinito. Ensayo sobre la exterioridad. Salamanca: Sígueme.

Moreno, D. P. (2016). Éticas ecofeministas: la comunidad de la vida. Cuadernos de Filosofía Latinoamericana, 36(113), 117-131.

Samour, H. (2005). El significado de la filosofía de la liberación hoy. Cuadernos de Filosofía Latinoamericana, 26(93), 130-147.

Semana. (11 de 2014). Semana.com. Aumenta la desigualdad entre hombres y mujeres. Obtenido de http://www.semana.com/vida-moderna/articulo/el-trabajono-remunerado-de-las-mujeres/410144-3 